\title{
THE RIGHT TO DEATH. FICTION OR REALITY?*
}

\author{
Maria Casandra Lucan, PhD student \\ West University of Timisoara, Faculty of Law \\ E-mail: casandra_lucan@yahoo.com
}

(Received November 2015; Accepted January 2016)

\begin{abstract}
The present article is part of a dense literature - result of a perennial debate - that has polarized societies for a long time and has evident reverberations in the present. It deals with "the right to death", trying to offer some answers referring to its existence in fact and the way in which it is perceived by different states and diverse entities with juridical nature. In the first part of the paper, it is insisted upon the right to life, so that subsequently, to speak in detail about a "right to death" and the moral and juridical implications of using such phrases. There are analyzed different states of the world found on one part or the other of the barricade in what concerns the legality of euthanasia and assisted suicide considered the two hypostasis of the right in question. It is offered, as well, an analysis of the Convention for the Protection of Human Rights and Fundamental Freedoms, mentioning that, paradoxically, while it cannot be modified so that it allows the appearance of some new rights, it can tacitly accept the creation by some states that have adhered to it of some rights antagonistic with those presented in its text. The conclusion, is that not any liberalization movement of a social action - quantified through the request of a right - has as a direct result a progress of the respective society, especially when the action creates something diametrically opposed to some fundamental functioning norms, such as, by excellence, the granting of the protection of life of all individuals.
\end{abstract}

Key words: right to life, right to death, fundamental rights, euthanasia, assisted suicide

\begin{abstract}
* This work was co-financed from the European Social Fund through Sectorial Operation Program Human Resources Development 2007-2013; project number POSDRU/187/1.5/S/155559, Competitive Multidisciplinary Doctoral Research in Europe.
\end{abstract}

\section{Introduction}

Over time, the majority of the philosophic and religious movements from all over the world have strongly condemned any act that could prejudice the human life. Nevertheless, once with the alert movement of more and more societies in an apparently progressive direction, life has lost the intangible human right character, becoming sometimes tributary to the appearance of the antithetic values, category in which the "right to death" is part.

In an era, dedicated to the constant enlargement of the human rights, the right to life is considered as being the supreme value on their scale, at international level (Streletz, Kessler and Krenz versus Germany 2001), being in the same time the 

non-existence of another right would be completely useless, because it is the foundation of all human rights and freedoms and the sine qua non condition for them. In the absence of life, the other rights do not have a sphere of applicability. Thus, before expressing a certain position regarding the right to death is absolutely necessary to reveal a few aspects of the right to life.

In time, once with the change of the moral standards that have appeared at a global level, a lot of infractions against life, incriminated by past generations, have been punished in the present in an attenuated form or even decriminalized. Two of these infractions are suicide and euthanasia in their different forms - receiving in the domain's literature the generic name of "right to death". These not only that interfere with the right to life voluntarily, but constitute themselves in its direct opponents.

Thus, suicide is the intentioned action of a person to take his life (Suicide 2010: 189-190), and euthanasia is the method to kill, without pain, a person who suffers of an incurable disease or a serious disability (Euthanasia 2010: 358). In our days, in Europe, Australia or the United States of America, suicide or suicide attempt are not incriminated, but in many Islamic countries (Lester 2006: 77-97), such as Singapore or Japan [2], suicide is illegal.

On the contrary, euthanasia has remained a moral, ethical and legal controversial problem, being in the present the most active research domain of Bioethics (Borry, Schotsmans, Dierickx 2006: 240-245) and each country has its own legal vision over this problem. Now, euthanasia is legal only in Holland, Belgium, Colombia, and Luxembourg, and assisted suicide is allowed in Switzerland, Germany, Japan Albania and certain states in the USA - Washington, Oregon, Vermont, New Mexico and Montana. The other countries still regard with skepticism the idea to give and protect a right to death. In Japan, although suicide is illegal, the euthanasia of a person can be legal, through the decision of the higher court, but also in absolutely exceptional cases.

\section{The right to life}

Before being regulated by the internal and international law, the right to life appears in the principles of religious doctrines from the earliest times, being even considered that "the history of the right to life combines with the history of humanity" (M'baye 1991: 111).

We can even affirm that the origins of the right to life are found in the natural right [3]. Natural rights differ from the human rights, because they are not created by the society in evolution; they were born from the laws of nature and the essence of human nature. On this base the human rights have appeared, as a subsequent phase. 
Lucan M.C. (2016)

The right to death. Fiction or reality?

From antiquity, the philosophers have debated the existence of some natural rights that an individual has. They are considered a given of nature, that has preceded the formation of modern political institutions. For example, the English philosopher John Locke has sustained the existence of these natural rights and has pleaded in the favor of a "state of nature" [4] in which all individuals are equal by birth and have the right to enjoy and defend their life, health, freedom and property (Locke 2011). Nevertheless, for the conservation and protection of these rights, people had to form social connections, which have led to the birth of the modern state. Thus, in Locke's opinion, the government's role was to preserve the individuals' natural rights. The rights have been codified and step by step there have been crated institutions cu protect them. In an ulterior stage, the states, noticing their common principles concerning human rights, have created international instruments for their protection, which they have adapted, gradually, in order to be in conformity with the values of a certain type of society. The Universal Declaration of the Human Rights (United Nations General Assembly 1948) and The American Declaration of the Rights and Duties of Man (Inter-American Commission for Human Rights 1948), both appeared in 1948, are the first international documents that identify clearly a right to life, in return, the European Convention for the Protection of Human rights and Fundamental Freedoms - enters into force in 1953 - is the one that has identified the first collective means to enforce this right.

\section{The vision of ECHR over the right to death}

The right to death is a moral principle based on the belief that a human being benefits of the means that allow him to commit a suicidal act or to undergo volunteer euthanasia. While some ask for its introduction in the category of civil rights, considering it and absolute and intangible right of a person (Curran, J.D., S.M. 1970: 167), others blame this idea and, moreover, even refuse to consider it a veridical right.

Most often, the discussion regarding the right to death is associated with subjects such as euthanasia and suicide, which, in fact, are nothing else but the legal implications of the right to death, in the modern vision. Of course, it is argued that suicide should be a civil right of the person, that no one can touch a d over which any authority should not have the power to intervene. This arguing line comes from the assumption that the possible self-murderer makes a rational choice between the extension of life and a quick death, considering his life of an unsatisfying quality. Until now, no international authority in the domain has clearly specified if an individual really has the right to take his own life, considering that life is a personal value a person can dispose of in conformity with his own choices and wishes. Furthermore, the European Court of Human Rights cannot interpret the European Convention of the Human Rights in the sense to create new rights, contrary to those already existing or not included at all in the Convention. ECHR cannot create 

because its interpreting power is limited: "It's Convention and Protocols must be interpreted in the lights of actual conditions. However, the Court cannot, through interpretative evolution, give birth to a right that has not existed from the beginning" (Johnston and others v. Ireland 1986). In conclusion, in no circumstances, the Court cannot give birth to new human rights that are not included in the present form of the Convention.

Moreover, by interpreting the Convention contra legem and allowing the formation of a right to death, ECHR would conceive a new right diametrically opposed to a right stipulated and guaranteed by the Convention. In our case, the right to euthanized or the right assisted suicide, both automatically implying a right to death, cannot be deduced from the Convention because it flagrantly breaks the stipulations of Article 2 that protects the right to life. Nevertheless, Article 2 sets certain exceptional cases [5], clearly defined, in which the right to death can be suppressed. The deduction by ECHR of other exception situations is not allowed and in consequence, the Convention must be interpreted as a "whole" (Haas v. Switzerland 2001).

Initially, the Court has avoided to clearly express it position concerning the negative implications of the right to life declaring in the case Widmer versus Switzerland (Widmer v. Switzerland 1993) that Article 2 "forces the states not only to hold back from actions that would intentionally cause death, but also take adequate measures in order to assure the protection of life". However, it was decided that the legal provisions by which Switzerland allows passive euthanasia does not break the Convention, taking into consideration that this state respects its duty to incriminate the offense of murder.

Subsequently, in the case Pretty versus Great Britain (Pretty v. Great Britain 2002), the Court has shown that Article 2 is drawn up in other terms than, for example, article 11 from the Convention, which regulates not only the right to free association, but also its reverse - the right not to be forced to associate (Udroiu 2014: 26). Article 2 refers to a "supreme" protection of life, having nothing to do with the aspects referring to the quality of life and not being able to be interpreted as a right to choose of an individual to do what he considers with his own existence.

Article 2 protects the existence of life itself and does not give to the person a right to choose of how to live his life or, relevant for the hereby article, how to stop its course. In this sense, the Court has considered impossible the interpretation of Article 2 without risking a language distortion, in the sense that it would give a right diametrically opposed to the right to life - the right to death. The Court did not convince that the right to life implies a negative side, also including the right to death or the right to determine a moment when a person chooses to die. The Court considers that Article 2, such as it is written in the present, does not guarantee 
anyone the right to death or the right to obtain medical assistance from another person during a suicide operation or even from the state, taking into consideration that it stipulates the obligation of the state to defend life. Although it would be admitted that the states which have legalized assisted suicide do not contravene with Article 2, it is impossible to accept that this law text creates an obligation for the states to allow euthanasia or assisted suicide. As a result, in this moment, the European Court leaves it up to the states the way in which they regulate the national legislation the problem of euthanasia or of the medically assisted suicide.

\section{The right to death in the practice of the national legislation}

In our opinion, the Court should adopt a clear position regarding the existence or non-existence of a right to death, because, in the present, the limits in the domain are unclear and can cause confusions, and this wish to evolve, in the future could create serious problems in what concerns the states that already heave highlypermissive conditions and which stubbornly sustain the existence of a right to death, under the double excuse, of the protection of human dignity and of the defense of the right to choose. In addition, we appreciate that although there exists the wish of social evolution, the creation of the right to death does not bring with it the expected evolution.

Like euthanasia, assisted suicide is a fresh subject on the daily order of many countries. Active or passive euthanasia must not be confused with medically assisted suicide, which implies the help offered by a doctor to a suffering that intends to suicide, by offering or indicating the lethal means (Udroiu 2014: 28). While the law is more and more permissive in certain countries that are representative in the domain, such as Holland and, Belgium, where euthanasia as well as assisted suicide takes place, these practices have remained controversial in other countries, such as Romania.

With the aim of a fake progress, when it comes about giving and protecting a so called right to death, the countries seem to influence one another. As a result, Belgium has followed the example of Holland, which in 2002 became the first country to legalize euthanasia, as a method to stop the sufferance for patients with the minimum age of 18 with incurable disease. In the meanwhile, under the auspices of the Groningen Protocol [6], in Holland has also become allowed in practice the euthanasia of children under 12, and from 28 February 2014 Belgium has extended its politics too regarding the controversial "right to die", including the access to euthanasia for seriously ill children. Thus, Belgium becomes the first country from the world that legalizes volunteer euthanasia of children without imposing an age limit, counting only on the decision of doctors, who analyzing each case, decide if the children sufficiently mature in order to decide if he wants to die and if his state condition is sufficiently bad and in the same time, impossible to improve, so that euthanasia is applicable. The reason of the legislator regarding 
Lucan M.C. (2016)

The right to death. Fiction or reality?

the modification of the law of euthanasia by including children in the category of patients that can benefit from it seems to have at its base the necessity to take into consideration the dramatic situations for which there has been no convincing answer at that moment.

The Belgian law is apparently clear regarding the possibility of a patient to receive, following a demand, assistance for suicide, stipulating a double condition. On one hand, the patient needs to take the decision voluntarily, without external pressures of any kind, and the demand must be subsequently reflected upon and repeated. On the other hand, the existence of an incurable disease in necessary, which implies a constant physical or mental sufferance, that cannot be attenuated (the Belgian Law regarding Euthanasia 2002 chap. 2, Section 3, Para. 1). Nevertheless, the law can be interpreted by the national courts in a discretionary way, so that a few controversial cases reveal. For example, in 2012, the Belgian doctors, following a court decision that has approved their demand, have euthanized the twins Marc and Eddy Verbessem. They have born deaf and were suffering from an incurable disease that was to leave them blind. It was motivated that the impossibility to communicate with one another, after a life spent together is unimaginable and the authorities have decided to allow the euthanasia even without the presence of a constant physical pain, in order to stop the existence of a future mental sufferance (Sommerville 2014: 218). Moreover, through the extinction of law in order to imply under aged persons, the Belgian authorities have embarked on a "slippery slope" - aspect that we consider problematic from various perspectives; but we stop at only mentioning the following: we mention that giving an under aged the responsibility of his own life, even in full command of mental faculties is a hasty gesture, since the legislation in force delegates to his legal tutor part from his rights and duties, considering an incapacity to take decisions - due to not arriving to a sufficient maturing stage.

In the case of Romania, the regulation by the New Penal Code - entered in force on $1^{\text {st }}$ February 2014 - of the offence of murder at the demand of the victim [7] as an attenuated form of murder, constitutes a rallying of the Romanian criminal law to the legislation of most European states. Thus, the New Penal Code incriminates active euthanasia [8] consisting of the action of a person by which he ends the life of the suffering patient, with his consent, as well as passive euthanasia [9] consisting of the production of the death of a sick person by not doing an act or by interrupting its realization that has a consequence death (Udroiu 2014: 28). In what concerns assisted suicide, the Romanian legislator incriminates it under the form of offense of causing or aiding suicide [10]. We consider that through the continuous incrimination of euthanasia, it is expressed a position that is relatively clear concerning $g$ a so said right to dignified death, which is considered an excuse in sustaining an apparent progress, which tends to become regress. 


\section{Conclusion}

We appreciate that there is no right to death in the international instruments of human rights protection, but there is a tacit acceptance of some legislative articles that allow the cessation of own life, by a volunteer act of the individual. The contrary support is mistaken, because it is based on an erroneous definition of the right to life. The right to life, considered a natural right, is the right of the human beings to live and it is opposable to those which tend to threaten them or suppress life. It is a supreme right and does not take into account qualitative aspects. Through the constant enlargement of the personal rights and freedom's area, the life, as a fundamental human value, has been frequently attacked. Thus the rights to choose have appeared - a complex and ambiguous area - that many states have decided to put on a high artificial pedestal. In order to offer an answer to the central question of this paper, also present in the title, in a simplified form: "Is the right to death a reality or something fictional?". I have researched this aspect from the national legislation's point of view, as well as from the international one, more exactly from the perspective of the ECHR. We conclude that the international instruments do not support the existence of a right to death, but on the contrary, it offers the right to life a leading position on the list of the rights that need to be protected. Even the syntagm "right to death", although used in the specialty literature, is improper and cannot be used when we refer to international documents that protect human rights. However, it must be mentioned that some states, taking advantage from the permeability of the texts of these instruments, which do not forbid expressly a right to death - but do not promote it in any way, have managed to legalize either assisted suicide, or euthanasia or both. As a consequence, the right to death has a fictional character in the European instruments of human rights protection, but the forms that derive from this are a reality of the national legislation of some states such as Belgium or Holland. We consider that through the promulgation of such laws that allow a "right to death" by the developed European states, which are expected to give positive examples, it is being abused of all that implies the notion of "right" itself and implicitly that of "right to life".

Finally, we can affirm that without a clear and guiding position regarding the subject, expressed by an authority in the domain, any argument, pro or con, gives birth to a series of complex and abstract questions regarding morality and the right to choose, to which the present article could not and has neither had the claim to answer exhaustively.

\section{Notes}

[1] Convention for the Protection of Human Rights and Fundamental Freedoms, Article 2 stipulates: paragraph (1) Everyone's right to life shall be protected by law. No one shall be 
Lucan M.C. (2016)

The right to death. Fiction or reality?

deprived of his life intentionally save in the execution of a sentence of a court following his conviction of a crime for which this penalty is provided by law.

[2] In Japan, suicide is illegal, but is not punished by law.

[3] The natural right is a doctrine based on the belief that there is a universal natural law that results from the divine order of the cosmos or from the rational and social nature of humanity.

[4] The state of nature is a concept in the political and moral philosophy used in domains such as religion, social contract theories, and international law in order to denote the hypothetical conditions of what the life of an individual would look like outside an organized society.

[5] Convention for the Protection of Human Rights and Fundamental Freedoms, Article 2 paragraph (2) stipulates: "Deprivation of life shall not be regarded as inflicted in contravention of this Article when it results from the use of force which is no more than absolutely necessary: (a) in defense of any person from unlawful violence; $(b)$ in order to effect a lawful arrest or to prevent the escape of a person lawfully detained; $c$ ) in action lawfully taken for the purpose of quelling a riot or insurrection."

[6] The Groningen Protocol is a text created in September 2014 at the University Medical Center Groningen (UMCG), which contains clear directives in order to establish under what conditions the doctors can euthanize children under 12 without criminal charges. Four conditions must be fulfilled cumulatively in this sense: the present of an unbearable sufferance, the consent of the parents, a previous medical consult and the careful execution of a euthanasia procedure.

[7] The offence of murder on the demand of the victim stipulated by article 190 from the New Penal Code consists of the murdering done at explicit, serious, conscious and repeated demand of the victim who suffers from an incurable disease or a medically assisted serious disability, causing permanent or difficult to bear sufferance.

[8] For example, the action of the doctor that gives a patient in the terminal phase an overdose of drugs that can lead to death.

[9] For example, the intended omission of the doctor due to treat the patient, to offer his necessary treatment, with the express aim to produce his death.

[10] The offense of causing or aiding suicide in it basic form stipulated by article 191 from the New Penal Code consists of the action to determine or facilitate the suicide of a person, if the suicide has taken place. The attenuated form of the offence consists of committing the action in its basic form or one of the aggravated forms, if the determining or committing acts were followed by a suicide attempt.

\section{References}

1. Borry P., Schotsmans P., Dierickx K. 2006: Empirical research in bioethical journals. A quantitative analysis. "J Med Ethics", XXXII/4, pp. 240-245.

2. Curran J. W, J.D., S.M. Hyg 1970: Suicide: Civil Right or Punishable Crime?, "Public Health and the Law" LX/1, p. 167.

3. European Council 1953: Convention for the Protection of Human Rights and Fundamental Freedoms, Strasbourg, Directorate of Information. 
Lucan M.C. (2016)

The right to death. Fiction or reality?

4. Eutanasia 2010: in Britannica Universal Encyclopedia (Vol. 5, p. 358), Bucharest, Litera Publishing

5. Haas versus Switzerland (European Court of Human Rights, 2011).

6. Inter-American Commission For Human Rights (IACHR): The American Declaration of Human Rights and Duties, Article 1, available at: http:///www.refword.org/docid/3ae6b3710.html (accessed in 1st October 2015).

7. Johnston and others versus Ireland (European Court of Human Rights, 1986).

8. Lester, D. 2006: Suicide and Islam, in "Archives of suicide research: official journal of the International Academy for Suicide research", X/1, pp.77-97.

9. Locke, J. 2011: Second treaties of Civil Government, Oregon, Watchmake Publishing.

10. M'baye, K. 1991: Les droits de l'homme et des peoples, Paris, A. Pedone Publishing, p. 111.

11. Pretty versus Great Britain (European Court of Human Rights, 2002).

12. Sommerville Margaret (2014), Exploring Interactions between Pain, Suffering and the Law, in "Suffering and Bioethics", Oxford University Press, p. 2018.

13. Streletz, Kessler and Krenz versus Germany (European Court of Human Rights, 2001).

14. Suicide 2010: in Britannica Universal Encyclopedia (Vol.14 pp. 189-190), Bucharest, Litera Publishing.

15. The Belgian Law regarding Euthanasia from 2002, Chap. 2, Section3, Parag. 1. 16. Udroiu, M. 2014: Dreptul penal. Partea Speciala, Noul Cod Penal, Bucharest, C.H. Beck Publishing, pp. 26-28.

17. United Nations General Assembly 1948: The Universal Declaration of Human Rights, 217 A (III), article 3, available at http:///www.refword.org/docid/ 3ae6b3712v.html (accessed on 28 September 2015).

18. Widmer versus Switzerland (European Court of Human Rights, 1993). 